dass in einer solchen Flüssigkeit ein saures Carbonat existirt, als dass sie eine mechanische Lösung von Magnesiumcarbonat in kohlensäurehaltigem Wasser repräsentirt. ${ }^{1}$

(Schluss folgt im nächsten Hefte).

\title{
Verwendung des Glimmers auf Stand - Gefässen.
}

\author{
Von B. O hm, in Pfalzburg.
}

In reichsländischen Apotheken findet man noch vielfach Papierschilder auf den Standgefässen. Da wo diese in durchsichtigen Gefässen selbst angebracht werden können, sind sie sehr haltbar, anders ist es aber bei Porzellan-, Holz- etc. Gefässen und solchen, die einen engen Hals haben. Bei einigermaassen frequentem Gebrauch oder ungeschicktem Anfassen leiden die Schilder sehr und müssen häufig durch neue ersetzt werden. Um diesem Uebelstande abzuhelfen, überklebe ich dieselben mit einer dünnen Glimmerplatte, sie erhalten hierdurch ein elegantes, den eingebrannten Schildern ähnliches Aussehen und grosse Haltbarkeit.

Herr Max Rafael in Breslau liefert 100 Glimmerplatten von Spielkartengrösse zu 25 Mark.

1) In der "British Pharmacopöia" vom Jahre 1867 finden wir einen Liquor Magnesiae earbonatis (Solution of earbonate of Magnesia), der durch Auflösung gefällter Magnesia alba in kohlensäurehaltigem Wasser dargestellt werden und in $28,3495 \mathrm{~g} .0,8424 \mathrm{~g}$. Magnesia alba enthalten soll. Auffälliger Weise normirt die genannte Pharmacopoe den Gehalt auf basisch kohlensaures Maguesium von der Zusammensetzung $3\left(\mathrm{MgCO}^{3}\right) \mathrm{MgO}+5 \mathrm{H}^{2} \mathrm{O}$, obgleich doch eine solche Verbindung keinesfalls in der Flüssigkeit enthalten soin kann. Richtiger wäre es gewesen, den Gehalt des Präparates auf $\mathrm{MgCO}^{3}+3 \mathrm{H}^{2} \mathrm{O}$ zu beziehen, wenn nicht überhaupt dieses überflüssig wäre, da ja die genannte Pharmacopoe am Schlusse des in Rede stehenden Artikels die Menge des Glührückstandes feststellt.

Auch eine englische Patentarznei ,Dinnefords pure fluid Magnesia“, die von London aus in circa je $180 \mathrm{~g}$. fassenden Gläsern in den Handel kommt, ist im Wesentlichen nichts weiteres, als eine verdünnte Lösnng von primärem Magnesiumcarbonat. Nach meiner Analyse enthält dieselbe, ausser Spuren von Chlormag. nesium und kleinen Mengen Magnesiumsulfat, $1,814 \% \mathrm{MgCO}^{3}+3 \mathrm{H}^{2} \mathrm{O}$. 